\title{
REAL TIME INVENTORY MANAGEMENT VISUAL SURVEY OF INTERIOR ARCHITECTURE ELEMENTS AND SPACE MAKING CRAFTS OF GUJARAT, INDIA
}

\author{
Rajdeep Routh $^{\mathrm{a}, *}$, Neha Singh ${ }^{\mathrm{b}}$, Piyush Shah ${ }^{\mathrm{c}}$ \\ ${ }^{a}$ Researcher, Design Innovation and Craft Resource Centre, CEPT University, Ahmedabad, India \\ routhrajdeep@gmail.com \\ ${ }^{\mathrm{b}}$ Researcher, Design Innovation and Craft Resource Centre, CEPT University, Ahmedabad, India \\ nehajsingh12@gmail.com \\ ${ }^{\mathrm{c}}$ Geospatial Specialist, TARU Leading Edge Pvt. Ltd., Gandhinagar, India \\ piyushsh18@gmail.com
}

\author{
KEY WORDS: Interior Architecture Elements, Space Making Crafts (SMC), Space Surface Crafts (SSC), Crafts inventory, \\ Visual survey, Open Data Kit
}

\begin{abstract}
:
In India, most of the inventories and documentations conducted for built heritage have been very nominal in nature and completely overlook the rich and opulent characters of the built form. This creates an imperative need of identifying and creating a detailed inventory of Interior Architecture (I.A.) Elements together with the SMCs and SSCs. This paper presents the process and the technique developed and termed as Real Time Visual Mapping (RTVM). RTVM is a procedure that incorporates the tablet survey, developed using open source tools, and is the first of its kind visual survey technique in India. The procedure comprises of an interactive form for mapping and helps manage the inventory generated from semi-urban and urban areas. The technique allows the user to transfer the mapped data in real time from the field, which can be produced through an interactive catalogue and map application. The recorded inputs reveal data ranging from type of elements to materials used, along with the various levels of traditional building crafts and expressions involved.
\end{abstract}

\section{INTRODUCTION}

India is a country rich in built heritage, and its documentation forms an integral part of understanding it. The documentation of built heritage, until recently, focused only the architectural aspects of the building and was customarily used for the conservation of the same. Because of these reasons, the focus has never been towards the mapping and documentation of the interior architectural elements, along with a spectrum SMCs and SSCs.

India has always had a varied range of traditional and vernacular building types. These buildings have always been defined by the Interior Architecture (I.A.) Elements along with the Space Making Crafts (SMC) and Surface making Crafts (SSC). According to the research undertaken at Design Innovation and Craft Resource Centre (DICRC), Space Making Craft (SMC) is the craft that is directly or indirectly related to the making of buildings, elements, furniture and its details. These coupled with the Space Surface Crafts (SSC), the crafts that are applied to the buildings, elements, furniture and its details; form a large repository of building craft techniques.

To understand and conserve our traditional and vernacular built forms, it is imperative to identify and create a detailed inventory of the numerous I.A elements and associated craft techniques which provide the cultural character to our built heritage. With this intention at the forefront, DICRC has initiated the process of mapping of the Interior Architecture Elements and the SMC/SSC. This process involves the process of on-site survey undertaken through the technique termed as Real Time Visual Mapping (RTVM).

RTVM has been developed specifically for the survey of Interior Architecture Elements and SMCs/SSCs involved and use an open source tool named Open Data Kit (ODK) for mapping, collecting and managing the information. The use of tablet survey is also done in exploring and identifying the prime specimens of our traditional buildings. The system involves extensive survey and involves public participation to develop an exhaustive inventory. The findings can be immediately uploaded to dedicated server in real time from the field and later be processed using Google Fusion Tables or KML files for cataloguing and further research. It is taken further in preparing an in-depth Traditional Building Portfolio (TBP) and Traditional Building Elements Catalogue (TBEC).

\section{TRADITIONAL AND VERNACULAR BUILDINGS}

India has always been a land of extreme geographical diversities. These varieties in the land features have thrown up a range of construction materials which have subsequently reflected on the built form and the construction techniques. Apart from the material availability and climatic constraints, the physical environment of a place is also effected by the rituals and culture of a civilization and its people. These cultural symbols and representations are very much evident in our traditional built forms, and distinguish them from one society to another. Right from the Himalayan settlements to the coastal 
house on the southern tip, India showcases a wide array of vernacular built forms which make the maximum use of native material. These materials range from stone to bamboo to mud, and helps create a region responsive architecture. These structures are also designed to withstand the effects of natural disasters like earthquakes and floods. Though the vernacular house types highlight the best use of the materials and construction techniques, they remain as an individual entity and underlines the ethnic believes in a primitive way. Gradually when the human race started settling in large groups, which we call urban centres, it gave rise to the various traditional dwelling typologies which are still visible in the numerous historic cities across the country.

The traditional house typologies found in the historic settlements have continually been developed through the years and it is the physical compendium of the construction and societal system. Along with the use of the locally available materials in a highly refined style, the traditional architecture at a place is also an embodiment of the social systems. Whereas the vernacular dwellings show a simplistic construction system with minimal expressions of the society, the traditional house form has gone through the evolutionary process. Gradually they ceased to be just buildings and also highlighted the community lifestyle and the belief systems along with various other aspects. These built forms thus serve a base for understanding the traditional systems of a society and its beliefs, along with its expressions.

The best mediums of expressing these cultural beliefs within a built form are through the SMCs/SSCs which can be seen on the space making elements. The SMCs and SSCs can be categorised into two sections respectively. There are two types of SMC, form-based and surface- integrated. Form-based SMC are the one those that make the different elements of the space (like stone masonry wall or wood turned table) and surfaceintegrated are those that give character to the surface of the elements of space through process of addition or subtraction (like wood carving or inlay). Similarly SSCs are categorised into Surface-clad and surface-finish. Surface-clad SSC are those which are cladded to any surface of elements of space (like tiles, flooring, fretwork) and Surface-finish SSC are the various types of finishes that are applied to any surface of elements of space (like gilding, painting).

\subsection{Traditional and Vernacular Buildings of Gujarat}

Gujarat lies on the western region of India, and is home to diverse beliefs and ethnicities. The state represents a microcosm of the Indian subcontinent, both in terms of geographical features and cultural traditions. The present location of Gujarat has been inhabited since earliest of civilisations and has imbibed several cultural influences starting from 300 years before Christ, which continued through the medieval times up to the British colonization of India. These numerous invasions and diverse influences have left a distinct mark, of each, on the society and its belief systems. Such effects, coupled with the geographic conditions, have steadily trickled onto the built forms seen within the state.

From having the longest coastline to the mountain ranges, from salt desert to dense rainforests, the state presents various climatic zones which shows on the built form. These varied physical conditions are visible on the built forms which have developed in different regions of the state and range from the bamboo houses in South Gujarat to the circular earth construction houses at Kutch. The domestic vernacular architecture of Gujarat showcases the paramount use of native materials under harsh climatic conditions, also making the best possible use of the construction knowledge. The best instance of this dwelling typology could be seen in the Bhunga houses at Banni, Kutch. These huts are constructed by the local craftspeople and constitute mud walls and thatch roofs. Though they lack visual charm from the exterior, they have elaborate mud and mirror work coupled with the murals and frescos on the interiors. They also vary from one locale to another, both in construction and expression, and form the identity of a community. These structures form the knowledge base for the development of the traditional house forms seen at the numerous places around the state (Figure 1).

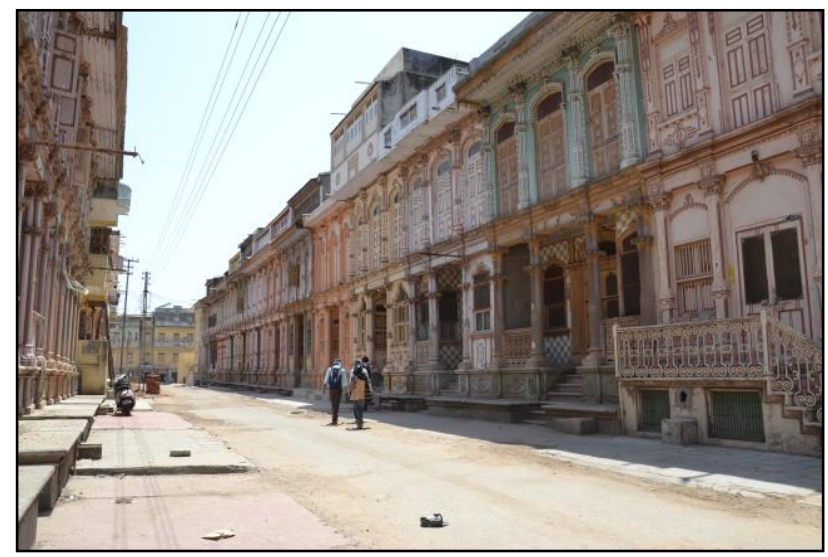

Figure 1. A traditional street from Sidhpur, Gujarat

The genesis of the traditional dwellings lie within the vernacular architecture and similarly have been hugely defined by the availability of the construction material. Endowed with such influences, we can today see the different traditional architecture spread across many historic settlements. These typologies range from the shared walled system of North and Central Gujarat to the individual house typology found in Saurashtra. They also underline a refined use of an array of locally available material, and vary from brick and timber to stone. Amongst all the typologies, the most common is that of the timber bonding with brick infill, and has been adapted all across Gujarat with minor alterations according to the climatic conditions and knowledge systems.

These cultural identities are conveyed through the spatial configuration of the house and the I.A. elements, and are considered as the symbol for the prevalent socio-economic condition of the era. The traditional house type has a substantial number of components which constitutes elements such as doors, columns, balcony, wall, ceilings, floors, staircases and windows amongst many. Apart from these I.A. elements, the furniture elements also lend to the character of the house. The furniture elements are probably the best source of gathering information about the inhabitants; the social status and way of life. The furniture elements are visible in numerous forms and according to the use can be categorised under wall units, seating, tables, beds, storage, light fixtures and many more. These elements highlight exquisite craft techniques and were regularly being adapted according to the need and cultural characters. The I.A. and furniture elements also highlight the high level of expertise the craftspeople achieved in their trade. A single façade door can possess varied materials and extreme heights of artisanship. An individual element can express 
different SMCs such as turning, carving, inlay and joinery at the same instance (Figure 2).

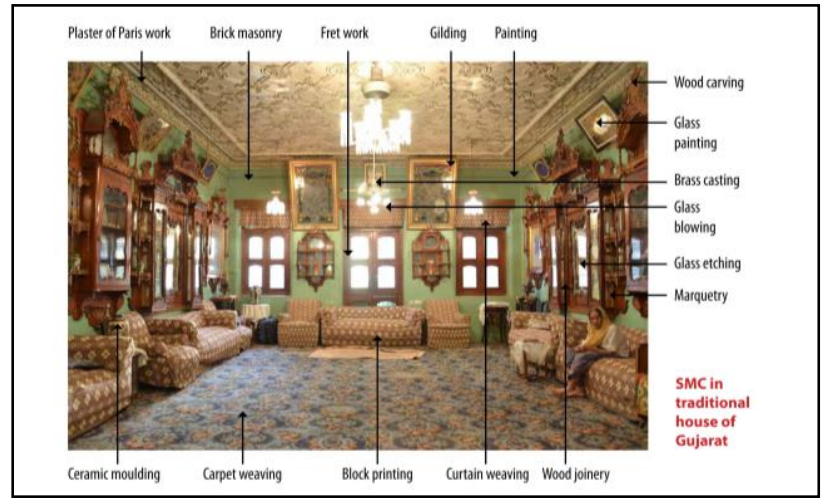

Figure 2. Space showing numerous craft techniques

These building elements have also undergone a lot of adaptations and alterations to develop a unique express of their own, and today is an amalgamation of various architectural styles. These styles can be broadly segregated into three eras, namely the Pre-Mughal, Mughal and Colonial, and covers a span of 400 years. During these eras, the styles range from the Hindu-Jaina, Mughal, Indo-Islamic to the Composite, Eclectic and Art-Deco styles prevalent during the British colonial days (Figure 3).

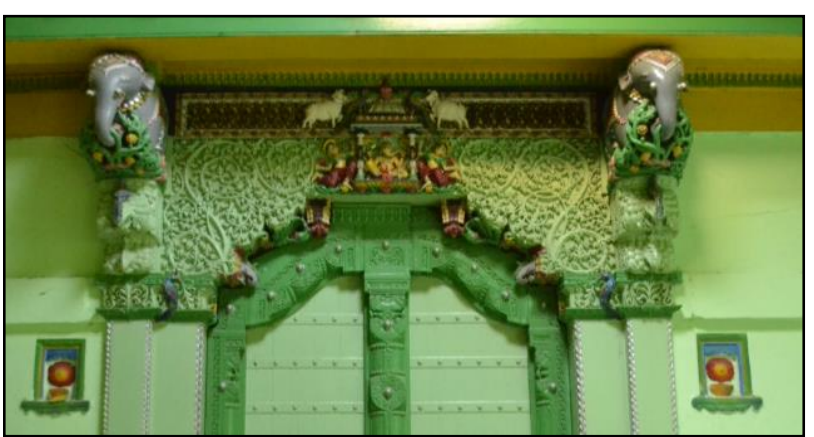

Figure 3. A traditional door highlighting the cultural influences

Along with the cultural influences, these developments within the I.A. and furniture elements together with the SMCs and SSCs can be credited to the craftspeople of Gujarat. The craftspeople were very industrious in nature and were also open new ideas and inspirations. As the craft was practiced for an entire time, the artisans developed their own versatile skills as well as individual knowledge which reflected on the elements. This creative brilliance of the craftsmen got illustrated in the way personalized adaptations of the ornamentations and the symbols. These vibrant building elements, combined with rich splendour of the interiors, demonstrate and exemplify the magnificence of the traditional built form and extreme qualities of the craftsmanship within the state of Gujarat.

\section{REAL TIME VISUAL MAPPING AT DICRC}

DICRC was established to function as an interface to understand and develop regional Space Making Crafts (SMCs) and Space Surface Crafts (SSCs) of traditional and vernacular buildings of India; and integrate them in the current InteriorArchitecture education as well as practice. The centre provides a conducive platform where design thinking engages with a range of SMCs/SSCs and traditional knowledge. The main aim of the research centre is to identify, understand, research, reposition and re-engage SMCs/SSCs and Craftspeople within building and habitat sector. The underlying objective is to combine crafts related to built environment and spatial design to explore new paradigms and solutions in current milieu. It seeks to be a hub for innovative thoughts and craft-design practices to engage and interact. Its major activities are to conduct research, documentation, organize programs, workshops, projects related to SMCs and SSCs.

One of the research project at DICRC aims towards developing a detailed inventory of such different types of buildings, its elements and the crafts; spread across the five regions of Gujarat. The visual mapping conducted across the state will showcase the essence and highest point achieved in our traditional and vernacular buildings as well as the SMCs/ SSCs integrated within it. Along with identifying the finest examples for such categories, the process also helps in developing and maintains a comprehensive catalogue of all essential facets of the built heritage. It will act as a common platform which puts all the finest examples of the traditional and vernacular building, I.A. and furniture elements as well as the SMCs and SSCs.

\subsection{The Visual Mapping Form}

RTVM is the first of its kind visual survey technique in India and the procedure comprises of an interactive form that is objective in nature. This makes the final interface easy to fill and acts as a model for mapping building elements and SMCs/SSCs. This further helps in managing the inventory generated from various parts of Gujarat. The use of tablet survey is also done in exploring our traditional and vernacular buildings. The visual mapping process involves a lot of public participation as it helps procure information about the place apart from creating awareness amongst the locals regarding the built heritage.

The process of RTVM was developed with the use of a tool named Open Data Kit (ODK). ODK is a free and open-source set of tools which helps the survey and management of mobile data collected. The three tools available within ODK - Build, Collect and Aggregate - were used for the purpose of developing the tablet mapping form. ODK Build lets the developer build the mapping form, which can later be used be on the mobile devices with the help of ODK Collect. The ODK Collect also provides the benefit of not preloading the tablet with mapping forms, as they can be downloaded from the server as per the need. The collected data can be then extracted in useful formats with the aid of ODK Aggregate (Figure 4).

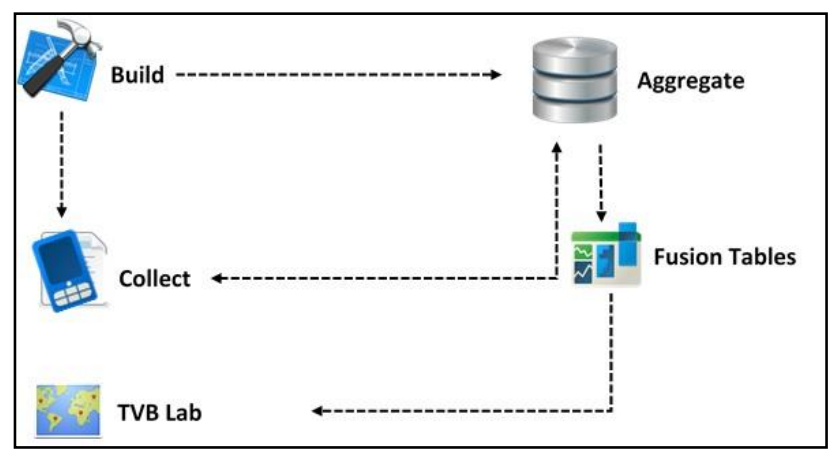

Figure 4. Process diagram of ODK used for RTVM 
The mapping form has been developed in two versions, named Building Mapping and Element Mapping. As the names suggest the respective forms help accumulate specific data, either pertaining to the space making elements crafts or the buildings which are worth documenting. The first form is relevant for gathering information regarding the examples of traditional and vernacular buildings which are worth documenting (Figure 5-6). The procedure starts with enquiring about the building typology and the accessibility, along with a façade image for reference. The form then collects information regarding the ownership and usage of the building. The mapping form also collects physical specifications of the built form; starting from the construction materials to the condition of the building. If the structure is found to be worth documenting, the form also has the provision of knowing the owner's willingness towards documentation and the GPS location of the property. The mapping limits itself to collecting the tangible information about the building along with the communication details.

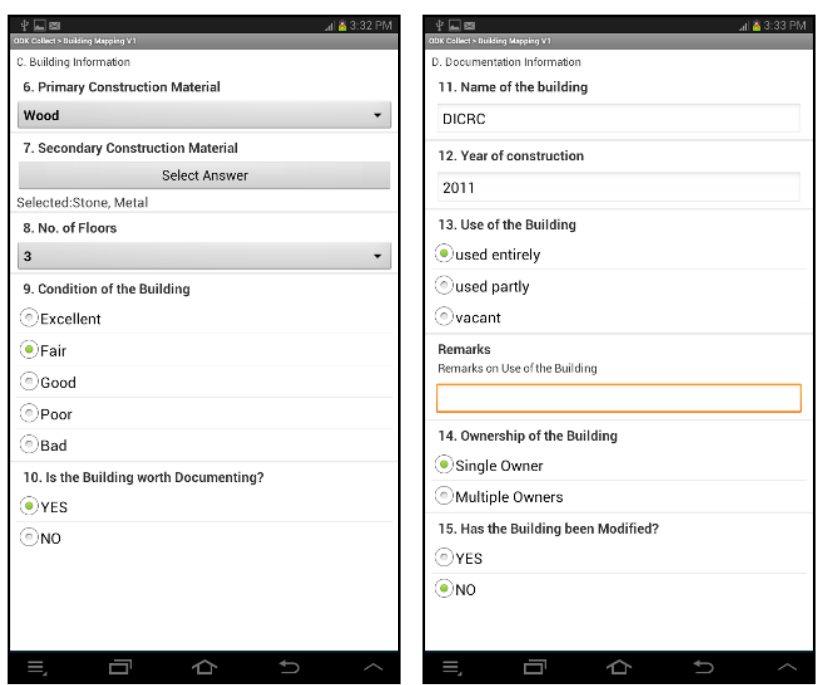

Figure 5-6. Excerpts from Building Mapping Form

The second part of the mapping is more extensive and involves the mapping of interior architecture elements and the SMC/SSC. Alike the building mapping form, the recording of elements also start with the information about the building type and its GPS location. The Element form is then segregated into two parts, Interior Architecture Elements and Furniture, as per the element which is being mapped and has various elements listed for each of the category (Figure 7). For instance, the I.A. elements have floor, ceiling, wall, balcony, doors, windows, columns, parapets, staircase and roof listed under itself (Figure 8).

The survey also has the provision to learn about the materials with which the element has been constructed and the relevant craft techniques which are visible on the element. The surveyor can select one or many materials depending on the element. The SMCs and SSCs are based on the individual materials which include wood, stone, earth, grass, metal and glass. A column made of wood will display techniques related to wood craft such as carving, inlay, lacquering, turning etc (Figure 9-10).

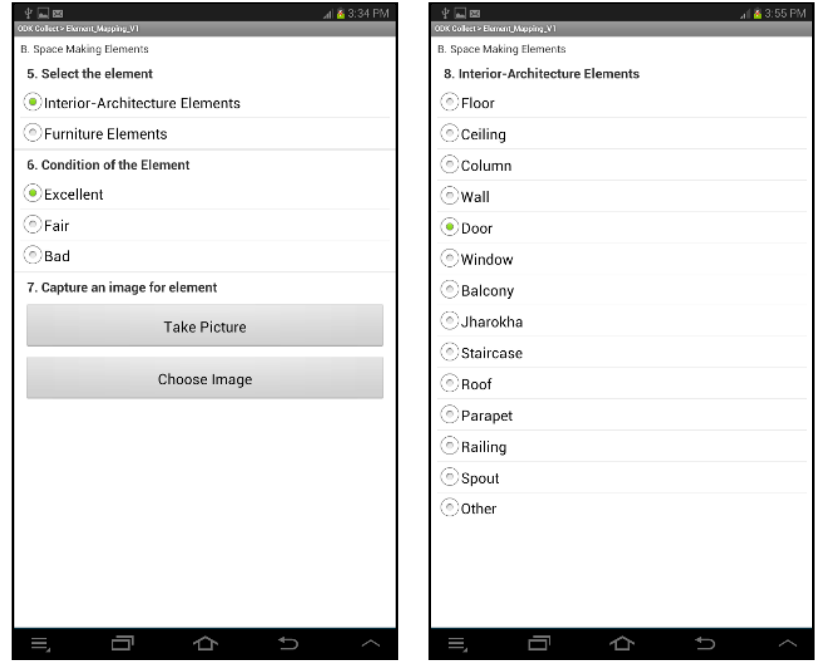

Figure 7-8. Information on the element type and condition

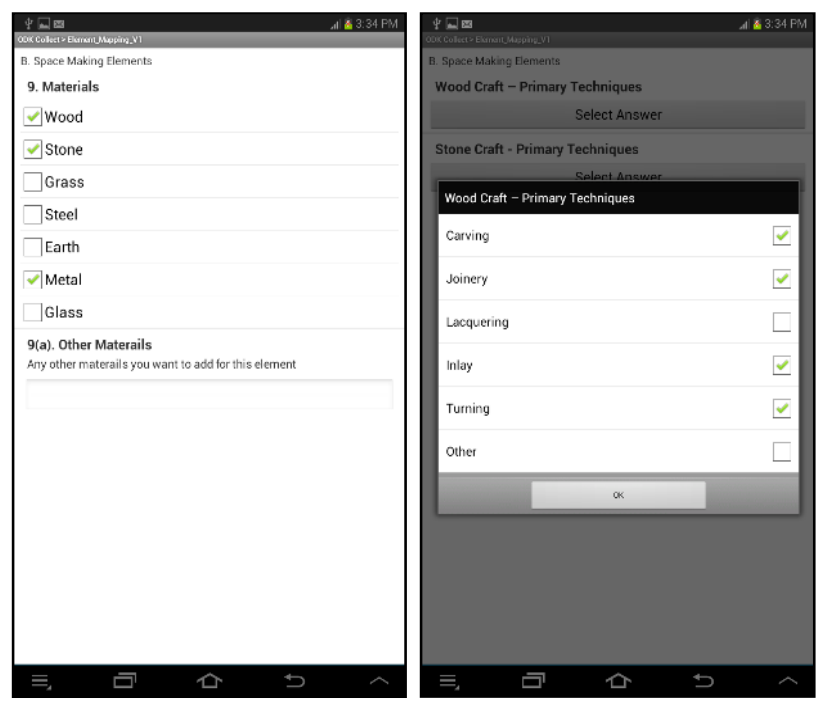

Figure 9-10. Material and crafts information from Element Mapping Form

\subsection{Visual Mapping}

For the purpose of conducting a well-managed mapping process, the state of Gujarat has been divided into five geographical regions; North, Central, Kutch, Saurashtra and South Gujarat. Every region has districts, within which places have been designated for the purpose of the study. All the five regions showcase different construction materials, building typologies and craft techniques. To map all the possible building typologies and the extensive list of building crafts, the research team form DICRC has travelled a large number of places within the state.

The mapping of the built forms along with the SMCs and SSCs can be considered the most exhaustive portion of the research project. The visual mapping involves a considerable amount of interactions with the local authorities and the people. Being new to a place, it is always beneficial to interact with the locals, so as to collect information about the precincts with high architectural value or the locals with knowledge about local craft techniques. The visual survey, apart from the mapping process, is also a discovery of the place, its people and cultural 
ethos. These findings also help in understanding the mapped elements, and the involved crafts and articulations in a better way.

The survey process is usually confined to the documentation of traditional and vernacular buildings, and involves covering the area on foot. The visual mapping involves two major processes, the survey form and the photography. The photographs are meant to click the individual elements in details along with capturing the images of the settlement. The images of the surrounding include the street photographs and the facades of houses with interesting features. The building elements which are elaborately crafted or show interesting use of materials are selected for the tablet survey. Such elements are mapped using the Element Mapping form and highlight the pinnacle achieved in the building trade and the craftsmanship. The buildings, mostly residential, which have highly fenestrated or remarkable facades with a few elements worth mapping, are selected to be mapped as a whole with the use of Building Mapping form. These houses may be classified as worth documenting, and has many Interior Architecture and Furniture elements mapped. The building survey process apart from mapping the elements and the house details, also involves interaction with the owner to investigate the history of the family and facts about the structure (Figure 11).
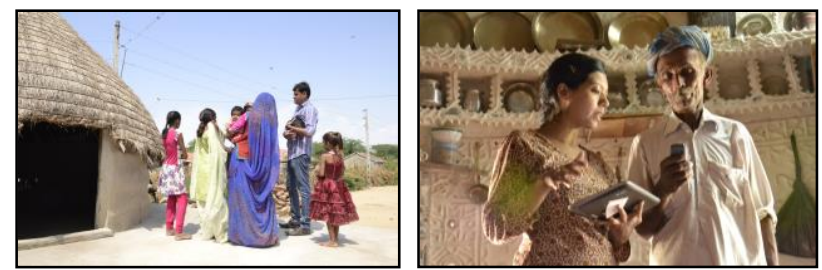

Figure 11. Researchers interacting with residents

Apart from taking the locations of the mapped elements and buildings, the area travelled within a particular place can also be marked using various tracking applications on the tablet. This shows all the streets and roads covered within the survey using GPS locations, thus indicating the areas covered and how much is left to mapped (Figure 12).

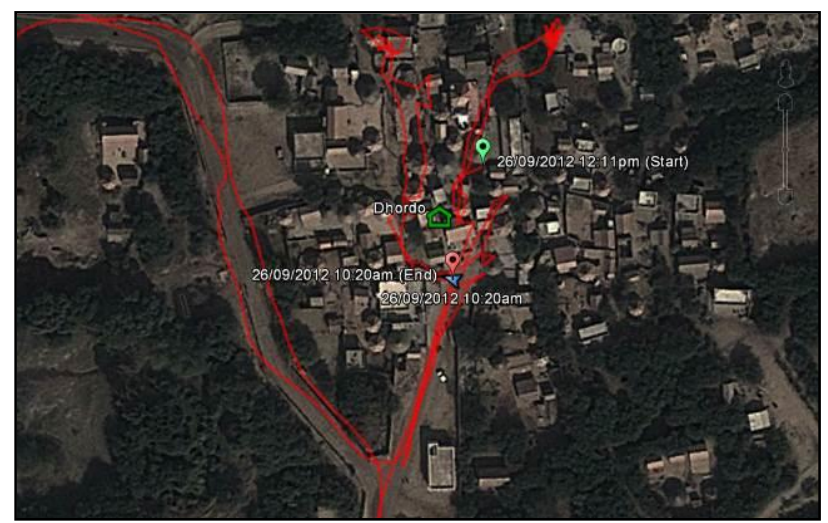

Figure 12. Route maps via Google Tracks

The technique allows the user to upload the findings immediately to dedicated server in real time from the field, and can be processed according to the usage.

\section{DATA OUTPUT AND MANAGEMENT}

This process uses Aggregate facility of the ODK, which helps manage the transferred data and use them in an organised way. Once the mapping data gets transmitted through the visual mapping from site, it gets delivered on to a dedicated server and is stored there. The ODK Aggregate allows the stored data to be displayed in a tabular form, and creates sections as per questions on the mapping form. This facilitates the study and analysis of elements and buildings, either within a single category or across various sections at the same time. ODK also enables the researchers to form analytical charts or pie diagrams to understand the mapped data (Figure 13-14).
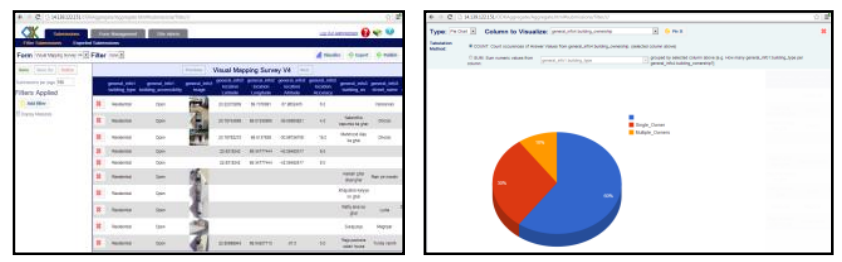

Figure 13-14. ODK Aggregate for data storage and analysis

The dataset can be exported in the form of CSV files for spreadsheets or as KML files for Google Earth, to analyse and understand the amount of data generated from the field work. This recordings could be also be transformed to Google Fusion Tables and directly be published on external systems for public viewing. The mapped data collected through the RTVM is disseminated in two main ways, Interactive Catalogue and Interactive Map Application, which are a part of TVB Lab developed by DICRC.The information, once received from the survey process, gets scrutinised and corrected of any errors. This dataset, through a content management system, gets catalogued and displayed on the DICRC web page (Figure 15).

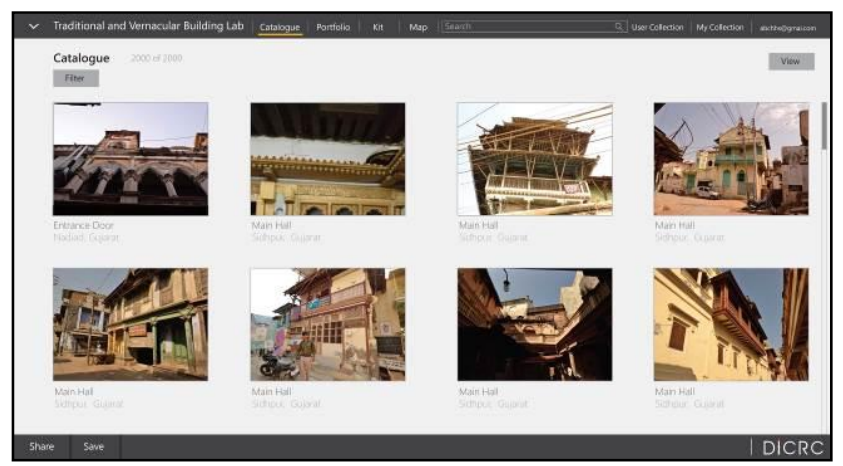

Figure 15. TVB Lab - Interactive Catalogue

This catalogue would be interactive in nature and will allow the user to browse the data through various parameters. One can search the mapped information under various categories such as usage of the building, interior architecture or furniture elements and the spaces where the elements have been used. It also permits the query generation with the catalogue through the materials used, crafts used and the various ornamentations involved (Figure 16).

For further research and future references, the users can also create customized personal collections of the elements and buildings according to the need. 


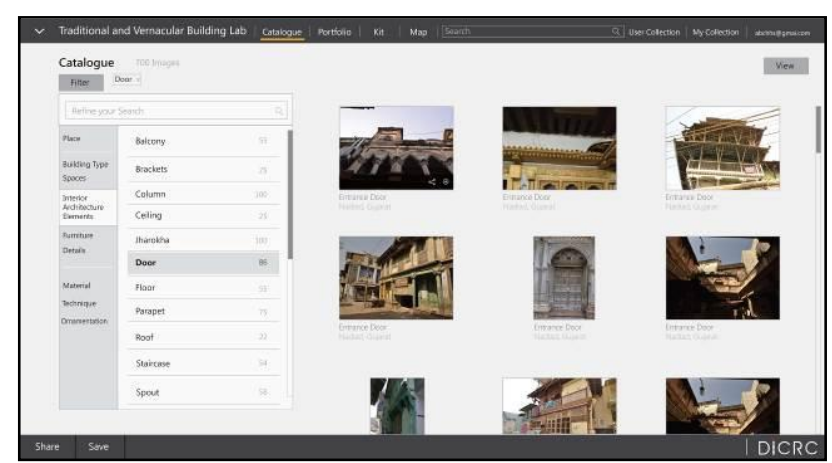

Figure 16. Search filters for the catalogue

For further research and future references, the users can also create customized personal collections of the elements and buildings according to the need.

The Interactive Map provides the geographical locations to all the surveyed buildings and its elements. For a certain location, the app along with the mapped information also provides the routes travelled during the mapping process. The app is segregated into two major categories, buildings and elements, using which a person can manoeuvre through the map. It provides the facility of generating a query in a similar way to the catalogue, and uses certain parameters for filtering the search. These query generators are similar to the ones used for the catalogue and range from element category to the materials and crafts involved. All the mapped data is represented through icons, which on clicking display information card of each. This information card shares information pertaining to the element selected, including the craft techniques and the use of materials for constructing it (Figure 17-18).
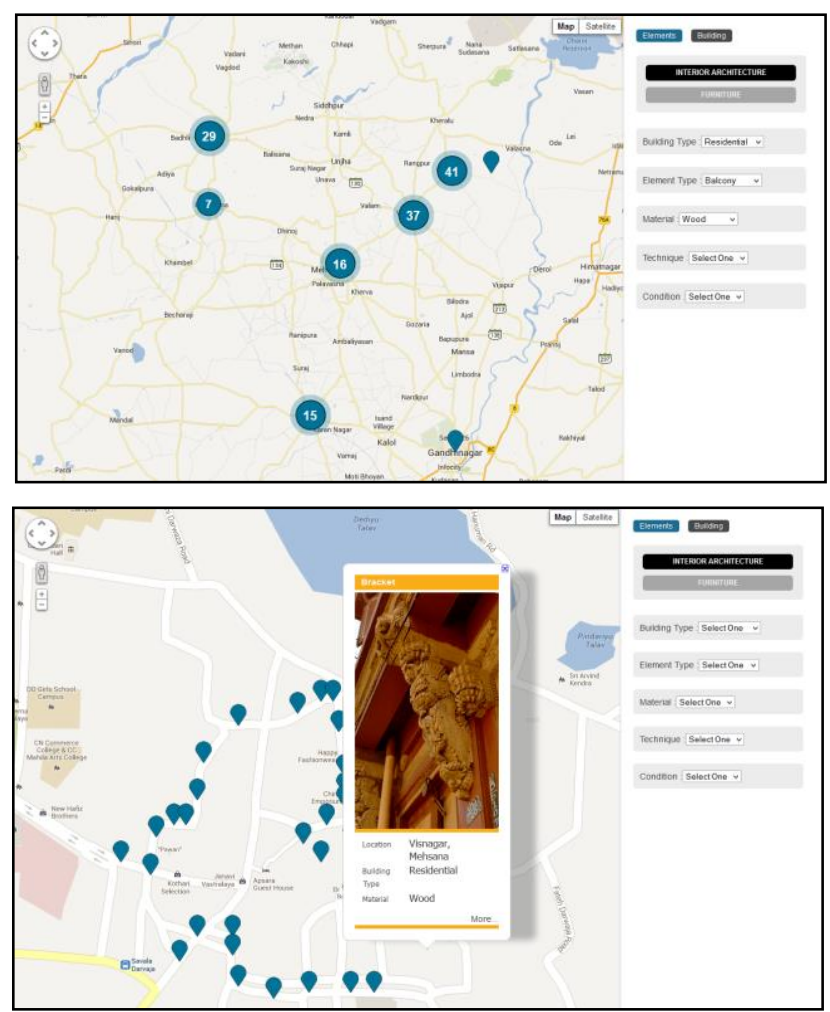

Figure 17-18. Map Application displaying mapped Interior Architecture elements
The information about the buildings worth documenting, from the visual survey, is further carried to formulate another research project undertaken at the DICRC. This work involves the documentation of traditional and vernacular houses, which highlight the traditional building knowledge along with remarkable use of localized construction materials.

\section{CONCLUSION}

In countries like India, which has a wide array of built forms and craft techniques, it is imperative to discover, analyse and manage all of them. This understanding is not rendered complete until there is detailed inventory generated which showcase the interior architecture elements, furniture and the craft techniques practiced. The process of Real Time Visual Mapping forms a first but significant step towards creating such a catalogue and managing it through various systems.

The RTVM involves the local participation in gathering the data and the process being mobile based makes itself user friendly, swift and inexpensive in nature. The simple interface allows many more users from various fields to get involved and contribute to the data collection, which can be validated by the experts. The form can also be easily adapted for survey in different regions of the country, even though the building and elements may differ in the making and expressions. Thus, RTVM produces comprehensive and meticulously catalogued information of the Space Making Crafts, related to Interior Architecture, of Traditional and Vernacular Buildings of India can be later integrated into the current Interior-Architecture practice as well as education. The information can also be used as a database towards crafts research and also for appropriate building conservation practices.

Since the development of Real Time Visual Mapping, it has been used to cover 26 of the 33 districts of Gujarat. Amongst these 26 districts, 76 settlements have been mapped to identify a total 110 building worth-documenting along with 4851 building and furniture elements.

\section{ACKNOWLEDGEMENT}

We want to register our acknowledgements to everyone who has contributed towards the research paper. We would like to especially thank Asst. Prof. Jay Thakkar, Head of Research at DICRC, for the constant ideas, discussions and support towards the development of RTVM. We would also appreciative of all the researchers at DICRC who have been part of the visual mapping process and have contributed towards it. We shall also extend our gratitude towards all the locals and property owners who have graciously helped developed the elaborate catalogue of buildings and craft techniques.

\section{REFERENCES}

Desai, M., 2003. Traditional House Type and the Building Craft of Gujarat. In: Traditional and Vernacular Architecture. Madras Craft Foundation, Chennai, India, pp. 53-63.

Thakkar, J., 2004. Naqsh-The Art of Wood Carving in Traditional Houses of Gujarat-A Focus on Ornamentation. Research Cell, School of Interior Design, CEPT, Ahmedabad, India. 